\title{
VISÃO EMPREENDEDORA NA APLICAÇÃO DO PLANEJAMENTO ESTRATÉGICO
}

Ana Beatriz Cavalcanti de Souza, Priscila Rodrigues Galindo Oliveira e Josélia Galiciano Pedro

Universidade do Oeste Paulista - Unoeste, Curso de Administração, Presidente Prudente, SP. E-mail: joselia@unoeste.br

\section{RESUMO}

Atrelado ao crescimento e ao desenvolvimento do empreendedorismo com o passar dos anos, tem-se o planejamento estratégico, um grande aliado para o auxílio nas tomadas de decisões, além de contribuir com a minimização de deficiências, prejuízos e maximização de lucros na organização. O objetivo desta pesquisa foi analisar as características do empreendedorismo associado ao planejamento estratégico e identificar as dificuldades que empreendedor encontra ao administrar o seu negócio, seja por necessidade ou oportunidade. Como metodologia o estudo teve como abordagem a qualitativa, a pesquisa exploratória e a pesquisa documental e como instrumentos de coletas de dados referências bibliográficas em livros, artigos científicos e consulta no site do SEBRAE, assim trazendo resultados significativos ao assunto. Dessa forma, a pesquisa demonstrou a importância do planejamento estratégico na visão empreendedora, independentemente do segmento de atuação ou do porte da organização.

Palavras-chave: Empreendedorismo. Planejamento Estratégico. Visão Empreendedora.

\section{ENTREPRENEURSHIP VISION IN THE APPLICATION OF STRATEGIC PLANNING}

\begin{abstract}
Linked to the growth and development of entrepreneurship over the years is strategic planning, in which it is a great ally to aid in decision making, as well as contributing to the minimization of deficiencies, losses and maximization of profits in the organization. The objective of this research will be to analyze the characteristics of entrepreneurship associated with strategic planning and to identify the difficulties entrepreneur finds when creating a new business, either by necessity or opportunity. As a methodology, the study will have as an approach the qualitative, exploratory research and using as instruments of data collection bibliographical references and consultation in the SEBRAE website, thus bringing significant results to the subject. In this way, the research project intends to reach its objectives of confirming that the entrepreneurial characteristics allied to the strategic planning techniques potentiate the success of the organization.
\end{abstract}

Keywords: Entrepreneur. Entrepreneurship Strategic Planning. Entrepreneurial Vision. 


\section{INTRODUÇÃO}

O empreendedorismo traz grandes contribuições para a economia do país, pois a geração de renda e a distribuição de bens e serviços são as principais fontes de receita de um país, bem como traz contribuições para a população que necessita de soluções para problemas cotidianos, soluções estas que, em sua maioria, são ofertadas através das organizações privadas. O contexto da figura do empreendedor diante da economia é de contribuição no desenvolvimento econômico do país, pois ele é visto como alguém que beneficia a sociedade em geral. O empreendedorismo é aliado ao planejamento estratégico nas empresas e novas organizações; apesar de muitos ainda não possuírem conhecimento sobre essa ferramenta, principalmente o Microempreendedor Individual (MEI), entre outros, eles até utilizam o planejamento estratégico, mas de forma indevida e incorreta, visto que o mesmo requer algumas habilidades específicas, mas totalmente adaptáveis a qualquer tipo de empreendimento. Esse desconhecimento de uma parcela das organizações sobre o planejamento estratégico deve-se também por certa dificuldade de comprometimento do mesmo, pois muitas vezes, o planejamento é apenas visto como previsão, projeção, plano, entre outros, mas todos possuem significados distintos apesar de parecidos. A problemática que orientou este artigo foi: De que maneira o planejamento estratégico influencia o empreendedor na administração do seu negócio? Este artigo teve como objetivo analisar a importância do empreendedor na prática do planejamento estratégico

\section{MÉTODOS}

A metodologia utilizada na elaboração da pesquisa foi composta de pesquisa exploratória, com abordagens qualitativa, documental e bibliográfica.

De acordo com Cervo, Bervian e Silva (2007, p. 63), "a pesquisa exploratória realiza descrições precisas da situação e quer descobrir as relações existentes entre seus elementos componentes, busca compreender um estudo ainda não explorado". Desse modo, foi analisado o papel do empreendedor ao aplicar o planejamento estratégico nas organizações.

Outro aspecto metodológico é a pesquisa qualitativa, a qual, segundo Fachin (1993, p. 75), "é caracterizada pelos seus atributos e relaciona aspectos não somente mensuráveis, mas também definidos descritivamente", ou seja, uma pesquisa com ampla extensão, que analisa e compreende diversas variáveis a fim de obter uma maior complexidade sobre um determinado assunto. Este estudo utilizou como método para coleta de dados a pesquisa bibliográfica em livros e artigos científicos para fundamentar a pesquisa. Foi utilizada também a pesquisa documental, através da consulta no site do SEBRAE para coleta de dados estatísticos, assim obtendo informações através dos estudos já realizados pela entidade referentes ao empreendedorismo.

\section{EMPREENDEDORISMO}

No Brasil, o movimento do empreendedorismo começou a tomar forma na década de 1990, quando entidades como Serviço Brasileiro de Apoio às Micro e Pequenas Empresas (SEBRAE) e Sociedade Brasileira para Exportação de Software foram criadas. Dornelas (2016, p. 20) diz que:

[...] antes disso, praticamente não se falava em empreendedorismo e em criação de pequenas empresas. Os ambientes político e econômico do país não eram propícios, e o empreendedor praticamente não encontravam informações para auxiliá-lo nesta jornada empreendedora. O SEBRAE é um dos órgãos mais conhecidos do pequeno empresário brasileiro, que busca junto a essa entidade todo o suporte de que precisa para iniciar sua empresa.

O estudo, então, confirmou que o empreendedor no Brasil até então não tinha nenhum espaço nem condições favoráveis junto ao governo para o auxílio na criação de novos negócios. Nos dias atuais, o empreendedorismo tem se tornado fundamental para o pleno desenvolvimento 
de um país, pois proporciona o crescimento econômico e, consequentemente, com a economia forte, gera mais empregos, aumentando a distribuição de renda e diminuindo até mesmo a desigualdade social.

É o que afirma Dolabela (2012, p. 21) quando diz que "o empreendedor é o responsável pelo crescimento econômico e pelo desenvolvimento social [...] o empreendedorismo é a melhor arma contra o desemprego". Quando o indivíduo reconhece e aproveita as oportunidades de negócios que surgem, aliando a capacidade que tem de explorá-las, beneficia toda a sociedade, seja na criação de novos empregos, seja no desenvolvimento econômico e financeiro do país.

Existem dois tipos de empreendedorismo: aquele buscado por necessidade ou o motivado por oportunidade. Mendes (2017, p. 4) relata que "o empreendedorismo por necessidade está relacionado a qualquer atividade profissional iniciada por indivíduos comuns, cuja única alternativa digna de sobrevivência em determinado momento de sua existência é a aventura por conta própria e risco no complexo mundo dos negócios". Assim, quando o indivíduo empreende por necessidade, é uma inevitabilidade para ele correr os riscos devido à ausência de trabalho e renda, já que a maior preocupação está na necessidade de sustento para ele e para sua família; este, normalmente, empreende sem nenhum planejamento.

Quando o indivíduo empreende por oportunidade, decide aumentar a renda, pois opta por iniciar um novo negócio, mesmo já tendo alternativa de trabalho, assim, "considera-se empreendedor por oportunidade aquele que abre uma empresa movido pela crença na identificação de uma oportunidade de negócio" (VALE; CORRÊA E REIS, 2014, p. 314).

O empreendedor por oportunidade avalia as oportunidades que tem, analisando o diferencial competitivo, o ramo de atividade e seu mercado, a fim de obter uma melhor análise estratégica e um planejamento da oportunidade de negócio. Para ser empreendedor não basta apenas ter um negócio próprio, é preciso ter características indispensáveis e fundamentais para o sucesso da organização e para que se tenha um resultado satisfatório do negócio iniciado.

Para Maximiano (2011, p. 4 e 5) são as características que se destacam:

Criatividade e capacidade de implementação - o empreendedor está sempre buscando coisas novas. Disposição para assumir riscos - [...] trata-se de uma aposta cujo resultado será influenciado pelos por fatores do ambiente externo e o trabalho duro. Perseverança e otimismo - 0 empreendedor tem um compromisso com a prosperidade do seu negócio. Senso de Independência - o empreendedor é um solitário [...] ele conta apenas consigo e mais ninguém.

Além dos riscos que o empreendedor está sujeito, terá também de enfrentar certas dificuldades. Segundo Chiavenato (2012, p. 21), "deve-se ter uma visão panorâmica e fortalecer a flexibilidade, a adaptabilidade e a manobrabilidade em um mundo dinâmico e complexo. No entanto deve-se também fugir dos perigos e percalços que rondam toda atividade criativa e inovadora." No caso do empreendedor, suas competências e capacidades são demandadas durante o percurso, porém, o empreendedor também tem o seu perfil, empreender está relacionado a criar coisas novas; logo, o empreendedor precisa ser criativo, ter ideias e anseio por mudanças, saber aproveitar as oportunidades usando sua capacidade de inovação.

\section{PLANEJAMENTO ESTRATÉGICO}

Segundo Oliveira (2014, p. 4), “[...] o planejamento estratégico corresponde ao estabelecimento de um conjunto de providências a serem tomadas pelo executivo para a situação em que o futuro tende a ser diferente do passado [...]". Diante do exposto, compreende-se que o planejamento estratégico é a junção de medidas que devem ser tomadas na organização na tentativa do futuro ser mais satisfatório que o passado, demonstrando, assim, seu alto grau de importância, o qual é ser melhor do que anteriormente. 
Entretanto, a concepção sobre a estratégia separadamente em uma empresa traz maiores dimensões do que se é o planejamento estratégico, pois, de acordo com Gamble; Thompson Junior (2012, p. 2): “A estratégia de uma empresa consiste nas iniciativas e abordagens desenvolvidas pela administração para atrair clientes e agrada-los, conduzir as operações, promover o crescimento dos negócios e atingir os objetivos de desempenho".

Demonstrando que a estratégia de uma organização engloba diversas variáveis desenvolvidas pela administração, com intuito de realizar uma aproximação entre empresa e clientes, buscando satisfazê-los, tem-se como função também alinhar as metas com os objetivos empresariais, sejam eles de sentidos abrangentes ou específicos.

De acordo com Maximiano (2011, p. 132):

Em algum momento do passado, os administradores de qualquer organização tomaram decisões estratégicas e aplicaram recursos para aproveitar oportunidades ou enfrentar desafios. Essas decisões trouxeram a organização até a situação em que se encontra no presente.

Sendo assim, compreende-se que toda organização possui estratégias, podendo ser elas explícitas ou implícitas, que, em sua maioria, são identificadas de forma informal principalmente em micro e pequenas empresas, mas que não deixam de ser relevantes e que norteiam a organização para chegar ao seu estado atual.

Compreendem-se como estratégias explícitas da organização conforme a mesma se formaliza. Sendo assim, essa formalização ocorre a partir do momento em que se cria um plano estratégico, o qual é a estrutura base que define os processos, metas e objetivos que a empresa deve desenvolver, demonstrando, assim, de maneira clara e objetiva, o que se pretende alcançar estrategicamente. Com relação às estratégias implícitas, observa-se o oposto das estratégias explícitas, a mesma se desenvolve na informalidade, ou seja, de forma não documentada e clara a toda organização e que, normalmente, é desenvolvida intrinsecamente pelo indivíduo responsável, visto que, dessa maneira, processos, metas e objetivos muitas vezes são pensados, mas não detalhados e analisados devidamente.

As estratégias implícitas ocorrem por tentativa e erro. Portanto, quando a elas estão em andamento, tem-se a impressão de intuição da parte do empreendedor/administrador que as desenvolve, devido a seu grau de abstração perante o restante da organização, mas, ainda assim, a estratégia pode ser identificada posteriormente com análise do seu passado.

No entanto, o planejamento estratégico envolve diversas variáveis para sua concepção. Dentre as etapas temos a análise da situação estratégica e análise do ambiente externo e interno, sendo essas de suma importância e de principal análise por parte do empreendedor no desenvolvimento de seu plano. Assim sendo, tem-se, como ponto de partida para elaboração do plano estratégico, o diagnóstico da situação estratégica, que compreende que a análise possui início em decorrência da missão da empresa, prática esta que permitirá o desenvolvimento de objetivos e metas.

\section{DISCUSSÃO}

Segundo análise da GEM (Global Entrepreneurship Monitor) publicado em 2016, foi identificado um conjunto de características na economia dos países que podem classificá-los como impulsionados por fatores, por eficiência ou por inovação. A impulsão da economia por fatores é aquela que possui, em sua maioria, grande dependência do fator trabalho e recursos naturais, ou seja, de um modo genérico, uma economia simples, menos avançada. Quando o país é identificado como impulsionado por eficiência, isso indica que ele possui características de avanços na industrialização e de economias de escala, demonstrando a maximização da utilização dos fatores produtivos, que, em sua maioria, reduzem custos consideráveis devido à grande proporção de compra de bens ou serviços, que, nesse caso, são inversamente proporcionais. 
Outro fator que classifica a impulsão por eficiência é quando o país possui maior parte das empresas intensivas em capital e, diante das pesquisas da GEM, o Brasil está indicado como país impulsionado por eficiência, enquadrando-se nas características descritas anteriormente. Já os países impulsionados por inovação são intensivos em conhecimento detêm grande domínio e habilidades de tecnologia; predominam também à amplificação e a modernização do setor de serviços.

Portanto, o entendimento sobre as características econômicas dentre os países e, principalmente, sobre o Brasil, demonstra a importância do empreendedorismo para com a economia, já que aqui é possível identificar onde o empreendedor está inserido, que tipo de legislação, o que o poder público do país enfatiza e como o mercado se movimenta. É importante destacar que, apesar do tipo de impulsão predominante no país em que o empreendedor está inserido, é possível o mesmo possuir posição de negócio diferente, desde que seja melhor que a anterior ou a atual, já prevendo os avanços do seu contexto econômico no futuro, tornando-se melhor preparado para quando esse momento chegar, estando, assim, um passo à frente da concorrência.

Segundo dados do SEBRAE (2016), no período de 2003 a 2016, o número de empreendedores no Brasil aumentou significativamente. Nesse mesmo período houve uma tendência no aumento crescente de empreendedores por oportunidade, chegando a representar $57 \%$, em 2016, e uma consequente queda no empreendedorismo por necessidade, já que as taxas apresentam correlação negativa, ou seja, quando uma aumenta a outra diminui.

Tabela 1. Motivação dos Empreendedores Iniciais 2016

\begin{tabular}{|l|r|r|r|}
\hline \multicolumn{1}{|c|}{ Motivação } & Taxas & $\begin{array}{r}\text { Percentual } \\
\text { da TEA }\end{array}$ & $\begin{array}{r}\text { Número de } \\
\text { Empreendedores }\end{array}$ \\
\hline Oportunidade & 11,2 & 57,4 & 15.022 .742 \\
\hline Necessidade & 8,3 & 42,4 & 11.113 .080 \\
\hline Razão Oportunidade/Necessidade & & 1,4 &
\end{tabular}

Fonte: GEM (2016, p. 30)

O aumento ocorreu devido à influência de vários fatores que promoveram a mudança, que vão desde o nível de escolaridade até a criação de uma rede de simplificação de registro e legalização de empresas, entre elas as Microempresas Individuais (MEI). Os índices demonstram que, em relação à taxa de empreendedorismo inicial, o Brasil tem maior equilíbrio comparado a outros países como os Estados Unidos, México e China, onde os indivíduos de renda mais elevada são mais ativos no empreendedorismo.

Sendo assim, a pesquisa aponta que, no Brasil, a maior parte dos empreendedores iniciais, que representam $71 \%$, possui renda entre um a três salários mínimos e que a maioria desses indivíduos não possui informações ou conhecimentos necessários para iniciar o próprio negócio e, ao longo da estabilidade do empreendimento, vai diminuindo o interesse pela ajuda. Essa falta de interesse aliada à falta de apoio das Políticas Públicas, das leis, entre outras é um dos motivos que levam muitos dos novos negócios a ir à falência antes mesmo de completar ao menos três anos de atividades.

Apesar do objetivo inicial do empreendedorismo por necessidade ser garantir a sobrevivência do indivíduo, o mesmo poderia ser tornar oportuno, duradouro e eficiente se planejado e orientado, mas, para isso, os empreendedores devem possuir maiores conhecimentos sobre a atividade que está desenvolvendo ou que pretende desenvolver, possibilitando, então, o desenvolvimento de um plano de negócio e um planejamento estratégico na organização. Para isso, os empreendedores têm disponíveis os órgãos ou agências de apoio, conforme tabela abaixo, na qual a GEM identificou os mais procurados e suas proporções dentre essa procura. 


\section{CONSIDERAÇÕES FINAIS}

Esta pesquisa buscou analisar a importância da aplicação do planejamento estratégico e sua contribuição na criação e iniciação de um novo negócio, independentemente do segmento de atuação ou porte, e como a falta desse planejamento pode interferir nos resultados. Com base nos dados do relatório da GEM, foi abordada a impulsão da economia por fatores, na qual o Brasil se enquadra como impulsionado por eficiência, indicando que o país possui grandes avanços industriais e na economia de escala. Outro fato que o estudo comprovou foi o crescimento de empreendedorismo por oportunidade, visto que hoje os indivíduos buscam realizar o sonho de ter o próprio negócio, o que antes era algo difícil de se realizar. Mostrou-se também os órgãos de apoio mais procurados que auxiliam os indivíduos na jornada do empreendedorismo. Assim, a análise dos dados foi de extrema relevância para o desdobramento da pesquisa científica e contribuiu, de maneira notável, para um melhor entendimento da importância do planejamento estratégico no empreendedorismo, assim como o desenvolvimento e a constante aprendizagem do empreendedor.

\section{REFERÊNCIAS}

CERVO, A. L.; BERVIAN, P. A.; SILVA, R. Metodologia científica. 6a ed. São Paulo: Pearson, 2007.

CHIAVENATO, I. Empreendedorismo: dando asas ao espírito empreendedor. 4ạed. Barueri: Manole, 2012.

DOLABELA, F. O segredo de Luísa. Rio de Janeiro: Sextante, 2012.

DORNELAS, J. Empreendedorismo transformando ideias em negócios. 6a ed. São Paulo: Atlas, 2016.

FACHIN, O. Fundamentos de metodologia. São Paulo: Atlas, 1993.

GAMBLE; THOMPSOM JUNIOR. Fundamentos da administração estratégica: a busca pela vantagem competitiva. 2a ed. São Paulo: AMGH Editora Ltda. 2012.

Global Entrepreneurship Monitor Empreendedorismo no Brasil: 2016 \Coordenação de Simara Maria de Souza Silveira Greco; diversos autores -- Curitiba: IBQP, 2017. Disponível em: <file:///C:/Users/PC/Downloads/GEM\%202016.pdf> Acesso em: 16 nov. 2017.

MAXIMIANO, A. C. A. Introdução à administração. 8a ed. São Paulo: Atlas, 2011.

MENDES, J. Empreendedorismo 360: a prática na prática. 3ª ed. São Paulo: Atlas, 2017.

OLIVEIRA, D. Planejamento estratégico: conceito metodologia práticas. 32a ed. São Paulo: Atlas, 2014.

SEBRAE: Relatório Especial: O empreendedorismo e o mercado de trabalho. Agosto de 2017. <https://m.sebrae.com.br/sites/PortalSebrae/estudos_pesquisas/relatorio-especial-oempreendedorismo-e-o-mercado-de-

trabalhodetalhe52,5cdfda0e84ebe510VgnVCM1000004c00210aRCRD> Acesso em: 24 Nov. 2017. 
VALE, G. M. V; CORRÊA, V. S; REIS, R. F. Motivações para o empreendedorismo: necessidade versus oportunidade? Rio de Janeiro - RJ, 2014 . Disponível em: <http://www.scielo.br/pdf/rac/v18n3/v18n3a05.pdf> Acesso em: 4mar.2018. 